\title{
Características clínicas y demográficas de pacientes con cáncer gástrico metastásico
}

\author{
- Pedro Luis Ramos Guette, María Athenas Ramos Escalante, Diana Silva
}

Oncológica Oncocare (Bogotá, D.C.)

Introducción: el cáncer gástrico es la primera causa de incidencia y mortalidad en Colombia. El propósito de este estudio es describir las características clínicas y demográficas de pacientes con cáncer gástrico metastásico.

Materiales y métodos: se trata de un estudio descriptivo, observacional de pacientes con cáncer gástrico metastásico atendidos durante el período del $1^{\circ}$ de enero de 2010 hasta el 31 de diciembre de 2016. Se realizaron análisis descriptivos usando medidas de tendencia central, ubicación y dispersión para las variables continuas, y frecuencias absolutas y relativas para las variables categóricas.

Resultados: se identificaron 56 pacientes en estado funcional de ECOG 0-1, todos recibieron tratamiento con esquema DCF. La edad promedio fue de 51,6 años, el sexo masculino fue de un $57 \%$ y el tipo histológico era difuso en un $71 \%$. La mayoría de las metástasis eran peritoneales, $57 \%$. La mediana de sobrevida libre de progresión está en 8,5 meses y la mediana de sobrevida global, en 18 meses.

Conclusiones: los pacientes con cáncer gástrico tienen compromiso metastásico más frecuentemente peritoneal y la histología más usual es difusa. La supervivencia global y libre de progresión de pacientes con cáncer gástrico es similar a la vista en la literatura. 